\title{
Molecular Cloning and Expression of a Synthetic Gene Encoding a $\beta$-glucosidase of Aspergillus Niger in the Methylotrophic Yeast Pichia Pastoris
}

\author{
Jean Louis Didier MEKOO (Corresponding author) \\ Minigene Pharmacy Laboratory, School of Life Science and Technology \\ China Pharmaceutical University, 24 Tongjia Xiang, Nanjing 210009, China \\ Tel: 86-25-83271369 E-mail: dimeko@live.ca \\ Yanan YANG \\ Minigene Pharmacy Laboratory, School of Life Science and Technology \\ China Pharmaceutical University, 24 Tongjia Xiang, Nanjing 210009, China \\ E-mail: yangsmay@163.com
}

Taiming Li

Minigene Pharmacy Laboratory, School of Life Science and Technology

China Pharmaceutical University, 24 Tongjia Xiang, Nanjing 210009, China

Rongyue CAO

Minigene Pharmacy Laboratory, School of Life Science and Technology

China Pharmaceutical University, 24 Tongjia Xiang, Nanjing 210009, China

E-mail: caorongyuenanjing@yahoo.com.cn

Jingjing LIU

Minigene Pharmacy Laboratory, School of Life Science and Technology

China Pharmaceutical University, 24 Tongjia Xiang, Nanjing 210009, China

E-mail: minigene1@yahoo.com.cn

\begin{abstract}
A 2526 bp gene encoding Aspergillus niger $\beta$-glucosidase was chemically synthesized for its heterologous expression in methylotrophic yeast Pichia pastoris, using methanol as inducer. The enzyme was purified from the induction medium to homogeneity by using ammonium sulfate precipitation, DEAE-cellulose chromatography and Sephadex G-200 gel filtration. The recombinant $\beta$-glucosidase catalyses the hydrolysis of cellobiose and salicin. The specific activity $(51.2 \mathrm{U} / \mathrm{mg})$ for cellobiose hydrolysis was enriched 7.4 fold with a recovery of $13.6 \%$. Optimum activity was observed in $\mathrm{pH} 5.0$ at $50^{\circ} \mathrm{C}$. The enzyme was a monomer with an apparent molecular mass of $90 \mathrm{kDa}$ as estimated by sodium dodecyl sulfate polyacrylamide gel electrophoresis.
\end{abstract}

Keywords: Chemical synthesis, $\beta$-glucosidase, Pichia pastoris, Methanol induction, Heterologous expression

\section{Introduction}

Cellulose, a polymer of glucose with $\beta-1,4$ linkages, is the world's most abundant natural biopolymer and a potential important source for production of industrially useful material such as fuels and chemicals. Ethanol is one of the most important renewable fuels, contributing to the reduction of negative environmental impacts generated by worldwide consumption of fossil fuels. Production of ethanol as renewable fuel from cellulose biomass is actively investigated (Lynd et al., 2002). However, the lack of biocatalysts and cellulase preparation for converting biomass into fuel ethanol has always been cited as roadblocks to bioethanol industry (Dien et al., 2003). Enzymatic hydrolysis of cellulose offers the potential for higher glucose yields and milder process 
conditions (Aristidou and Penttila, 2000). The complete degradation of cellulose involves a synergistic action of three main cellulolytic enzymes. These enzymes include: a) $\beta-1$, 4-endoglucanase (EC 3. 2. 1. 4) which randomly cleaves internal $\beta$-1,4-glycosidic bonds; b) Cellobiohydrolases (EC 3. 2. 1. 91) sequentially releases molecules of cellobiose from reducing and non-reducing ends of cellulose and c) $\beta$-glucosidase ( $\beta$-D-glucoside glucohydrolase; EC 3. 2. 1. 21) that hydrolyses cellobiose to glucose which can then further be converted to other chemicals such as ethanol (Bhat and Bhat, 1997). The presence of $\beta$-glucosidase in cellulase preparations has been reported to stimulate the rate and extent of cellulose hydrolysis (Ryu and Mandel 1980; Wood and McCrae, 1982). This effect has been explained by the concept that it relieves the inhibition by cellulose-derived cellobiose of cellulase activity, as both endoglucanase and exoglucanase activities are often inhibited by cellobiose. Developing cellulase enzymes, and preferably, suitable microorganisms that produce such enzymes which can be used for the efficient depolymerization of a complex sugar and subsequent rapid fermentation of the sugar into alcohol would be of great benefit. Various cellulases and $\beta$-glucosidase genes have been expressed in Saccharomyces cerevisiae with aim of direct ethanol production from cellulose (Van Rensburg et al., 1998; Jeon et al., 2009; Fujita et al., 2002, Hong et al., 2006). The methylotrophic yeast Pichia pastoris is a powerful tool for the heterologous expression of proteins (Cereghino and Cregg, 2000). The increasing popularity of this expression system can be attributed to several factors, such as the simplicity of techniques needed for the molecular genetic manipulation of $P$. pastoris, many eukaryotic posttranslational modifications and high-level gene expression (Hasslacher et al., 1997; Hollenberg and Gellissent, 1997; Sreekrishna et al., 1997). Protein expression in P. pastoris is based on the use of the alcohol oxidase 1 (AOX1) promoter. This promoter is strongly induced by methanol (Li et al., 2007). Chemical synthesis is an attractive alternative to conventional gene cloning for the reason that codon usage can be optimized for the proposed organism of expression favoring high yields of protein. In this work, we used a synthetic gene encoding a $\beta$-glucosidase from Aspergillus niger to develop a recombinant yeast Pichia pastoris expressing a cellobiase activity. Expression, structural and functional characterizations of the yeast synthesized polypeptide are described.

\section{Material and Methods}

\subsection{Strain, plasmid and medium}

Escherichia coli (E. coli) DH5 $\alpha$ was used as a host for sub-cloning. Pichia pastoris GS115 was used as a host for expression. Plasmid pPIC9K was used for expression. E. coli was cultured in Luria-Bertani (LB) broth (1\% tryptone, $0.5 \%$ yeast extract, $0.5 \% \mathrm{NaCl}$ ) or on $\mathrm{LB}$ agar plate. When needed, ampicillin was added at a concentration of $100 \mu \mathrm{g} / \mathrm{ml}$. The expression strains were screened in minimal dextrose (MD) medium [1.34\% yeast nitrogen base (YNB), $0.00004 \%$ biotin, $2 \%$ dextrose] and minimal methanol (MM) medium $(1.34 \%$ YNB, $0.00004 \%$ biotin, $0.5 \%$ methanol). Yeast was cultured in yeast extract peptone dextrose (YPD) medium (1\% yeast extract, $2 \%$ peptone, $2 \%$ dextrose, $2 \%$ agar), buffered glycerol-complex (BMGY) medium (1\% yeast extract, $2 \%$ peptone, $100 \mathrm{mM}$ potassium phosphate, $\mathrm{pH} 6.0,1.34 \% \mathrm{YNB}, 0.00004 \%$ biotin, $1 \%$ glycerol) and induced in buffered methanol-complex (BMMY) medium (1\% yeast extract, $2 \%$ peptone, $100 \mathrm{mM}$ potassium phosphate, $\mathrm{pH} 6.0,1.34 \% \mathrm{YNB}, 0.00004 \%$ biotin, $1 \%$ methanol).

\subsection{Construction of cloned $\beta$-Glucosidase expression vector}

A gene encoding a $\beta$-glucosidase ( $\beta$-Gl2) from Aspergillus niger was designed according to its nucleic acid sequence published at GenBank (Accession $n^{\circ}$ EU233788.1). This sequence was synthesized by Shanghai Sangon Bioengineering Company (Shanghai, China) and cloned into pUC19 plasmid named pUC19- $\beta-$ Gl2. DNA manipulations and subcloning were performed according to standard procedures (Sambrook and Russell 2001). The full-length sequence of $\beta-G 12$ without the signal peptide was amplified from pUC19- $\beta-G 12$. PCR reaction, using ExTaq polymerase (TAKARA), was as follows: Denaturation $5 \mathrm{~min}$ at $94^{\circ} \mathrm{C}, 30$ cycles of denaturing at $94^{\circ} \mathrm{C}$ for $45 \mathrm{sec}$, annealing at $59.1^{\circ} \mathrm{C}$ for $1 \mathrm{~min}$ and elongation at $72^{\circ} \mathrm{C}$ for $3 \mathrm{~min}$. Forward primer 5'- AATACGTAGATGAATTGGCCTACTCC - 3 ' ATAGTTTAGCGGCCGCTTAGTGAACAGTAGGCA - 3' were designed to introduce SnaBI and Not I restriction sites (underlined) respectively. Amplified PCR product was resolved by $0.8 \%$ agarose gel electrophoresis. The gel slice containing the expected size band was excised and extracted with SANGON gel extraction kit. The purified $\beta$-Gl2 fragment was first treated with restriction enzymes and then ligated, using DNA ligation kit (Takara), to the purified SnaBI-Not I double-digested secretory expression vector pPIC9K. E. coli strain DH5 $\alpha$ was transformed with the ligation mixture. Bacterial transformants were selected for their ability to grow in LB medium in the presence of $100 \mu \mathrm{g} / \mathrm{ml}$ ampicillin. Transformants were screened by colony-PCR using the above primers. The recombinant expression vector, designated as pPIC9K- $\beta$-Gl2, was then prepared using a plasmid miniprep kit, identified by double enzyme digestion and insert further sequenced by GenScript. 


\subsection{Construction and screening of $P$. pastoris expression strains.}

pPIC9K- $\beta$ Gl2 used for transformation was linearized by PmeI. P. pastoris GS115 strain was made competent and transformed with PmeI-linearized pPIC9K- $\beta$ Gl2 by electroporation following INVITROGEN protocol. About $10 \mu \mathrm{g}$ of linearized vector and $80 \mu \mathrm{l}$ of electro-competent GS115 cells were used. Immediately after pulsing $(1.5 \mathrm{kv}, 5 \mathrm{~ms}), 1 \mathrm{ml}$ of cold $1 \mathrm{M}$ sorbitol was added to the cuvette. After incubation of $30 \mathrm{~min}$ at $30^{\circ} \mathrm{C}$, cells were plated on MD medium and incubated at $30^{\circ} \mathrm{C}$ and monitored each day till appearance of colonies. His ${ }^{+}$ transformants in each plate were resuspended in $2-3 \mathrm{ml}$ of sterile water and thereafter pooled. The cells density was determined by reading OD at $600 \mathrm{~nm}$. Then $10^{5}$ cells were plated on MD plates containing increasing concentrations of G418 from 0.25 up to $4 \mathrm{mg} / \mathrm{ml}$ to screen for multi integrant transformants.

\subsubsection{PCR analysis of Pichia integrants}

Yeast genomic DNA was extracted from selected clones grown overnight in $5 \mathrm{ml}$ YPD as follows: Cells from 1.5 $\mathrm{ml}$ of the cultures were pelleted in a microcentrifuge tube and the cell pellets were resuspended in $200 \mu$ of lysis buffer [2\% Triton X-100, 1\% SDS, $100 \mathrm{mM} \mathrm{NaCl}, 10 \mathrm{mM}$ Tris- $\mathrm{HCl}$ (pH 8.0), $1 \mathrm{mM}$ EDTA (pH 8.0)] (Harju et al., 2004). $200 \mu \mathrm{l}$ of phenol-chloroform (1:1) and $0.3 \mathrm{~g}$ acid washed glass beads were added and the tubes were vortexed for 2 minutes. Thereafter $200 \mu \mathrm{l}$ TE buffer pH8 were added to tubes, followed by 5 minutes centrifugation $12,000 \times \mathrm{g}$ at room temperature. The aqueous layer was transferred to a tube containing $1 \mathrm{ml}$ of ice-cold $100 \%$ ethanol. The samples were allowed to precipitate 5 minutes at room temperature and then centrifuged 2 minutes at room temperature at $12,000 \times \mathrm{g}$. Supernatants were poured off and DNA pellets reconstituted in $400 \mu \mathrm{l}$ TE buffer $\mathrm{pH} 8$ containing $30 \mu \mathrm{g} / \mathrm{ml}$ RNase A and incubated for 5 minutes at $37^{\circ} \mathrm{C}$. Then, $18 \mu \mathrm{l}$ of $3 \mathrm{M}$ ammonium acetate and $1 \mathrm{ml}$ ice-cold $100 \%$ ethanol were added and tubes were kept at $-20^{\circ} \mathrm{C}$ for few hours. DNA was spun down 10 minutes at $12,000 \mathrm{x}$ g resuspended in $25 \mu 1$ water. The so-extracted DNA served as a template for Taq DNA polymerase PCR using 5'AOX1: 5'-GACTGGTTCCAATTGACAAGC-3' and 3'AOX1: 5'-GCAAATGGCATTCTGACATCC-3' primers (Invitrogen)

\subsection{Pichia expression studies}

Single colony of one the positive transformants was grown at $30^{\circ} \mathrm{C}$ in $25 \mathrm{ml} \mathrm{BMGY}$ medium in $250 \mathrm{ml}$ flasks for 16 to $20 \mathrm{~h}$ with vigorous shaking $(225 \sim 250 \mathrm{rpm})$ until an $\mathrm{OD}_{600}$ value of $2-5$ had been reached, then harvested by centrifugation at $3000 \mathrm{~g}$ at $25^{\circ} \mathrm{C}$ for $5 \mathrm{~min}$. Supernatant was decanted and the cell pellet was resuspended to an $\mathrm{OD}_{600}$ of 1.0 in induction medium BMMY in 11 flasks and allowed to grow at $30^{\circ} \mathrm{C} .1 \%$ (final concentration) methanol was added to the flask every $24 \mathrm{~h}$ in order to maintain induction. Supernatants were taken after induction for $0 \mathrm{~h}, 12 \mathrm{~h}, 24 \mathrm{~h}, 36 \mathrm{~h}, 48 \mathrm{~h}, 60 \mathrm{~h}, 72 \mathrm{~h}$ and $84 \mathrm{~h}$ for sodium dodecylsulfate-polyacrylamide gel electrophoresis (SDS-PAGE) analysis using 10\% acrylamid gel (Laemmali, 1970).

\subsubsection{Production and purification of the recombinant $\beta$-glucosidase}

Recombinant $P$. pastoris was cultured in BMGY and induced in BMMY as previously described. Expression was induced for 60 hours at $30^{\circ} \mathrm{C}$ under shaking and the cell-free extract obtained after centrifugation 3000xg for $5 \mathrm{~min}$ at $25^{\circ} \mathrm{C}$ was used as the "crude extract". Ammonium sulfate fractionation: The crude extract $(360 \mathrm{ml})$ was fractionated by gradual addition of solid ammonium sulfate to give $30 \%$ saturation with stirring at $4{ }^{\circ} \mathrm{C}$ for 3 hours. After, the mixture was centrifugated at $12000 \mathrm{xg}$ for $15 \mathrm{~min}$. Solid ammonium was added to the supernatant to $80 \%$ saturation and the solution was stirred overnight at $4{ }^{\circ} \mathrm{C}$ and thereafter centrifugated at 12000 $\mathrm{g}$ for $20 \mathrm{~min}$. The precipitate was resuspended in $50 \mathrm{mM}$ citric-phosphate buffer $\mathrm{pH} 6$ and dialyzed overnight at $4^{\circ} \mathrm{C}$ against $10 \mathrm{mM}$ phosphate buffer $\mathrm{pH} 7$. Ion exchange chromatography: The dialysate was loaded onto a DEAE-32 (Pharmacia) column $(1.9 \mathrm{~cm} \times 30 \mathrm{~cm})$ pre equilibrated with $10 \mathrm{mM}$ phosphate buffer $\mathrm{pH}$. The elution was performed with the starting buffer ( $\sim 2.8$ column volume) and then a gradient of $0-0.3 \mathrm{M} \mathrm{NaCl}$ in $10 \mathrm{mM}$ phosphate buffer $\mathrm{pH}$. The column was washed with $0.5 \mathrm{M} \mathrm{NaCl}$ in $10 \mathrm{mM}$ phosphate buffer $\mathrm{pH} 7$. Fractions containing $\beta$-glucosidase activity were pooled and concentrated through Amicon Ultra Centrifugal Devices, MW cut off 10,000 (Millipore) at 7,500xg for $10 \mathrm{~min}$ at $25^{\circ} \mathrm{C}$. The sample was dialyzed overnight at $4{ }^{\circ} \mathrm{C}$ against $10 \mathrm{mM}$ phosphate buffer $\mathrm{pH}$. Gel filtration: The filtrate was further chromatographed on a Sephadex G-200 (Pharmacia) column using $10 \mathrm{mM}$ phosphate buffer $\mathrm{pH} 7$ as elution buffer. Active fractions were pooled and dialyzed against $10 \mathrm{mM}$ phosphate buffer $\mathrm{pH} 7$ then concentrated by ultrafiltration. The filtrate was the "purified enzyme". Purity was monitored throughout the fractionation by SDS-PAGE. Detection of $\beta$-glucosidase in eluates was carried out using 4-methylumbeliferyl- $\beta$-D glucopyranoside (MuGlc) as substrate for enzyme reaction. $10 \mu 1$ of each sample was placed on $3 \%$ agar plate containing $0.2 \mathrm{mM}$ MuGlc in $50 \mathrm{mM}$ citric-phosphate buffer $\mathrm{pH}$. The plate was then incubated at $50^{\circ} \mathrm{C}$ for 1 hour and thereafter illuminated with UV light. An intense fluorescence was an indicator of $\beta$-glucosidase activity. 


\subsubsection{Enzyme assay}

Protein concentration was determined spectrophotometrically by coomassie (BRADFORD) Protein Assay, using the protein assay kit (Nanjing Jiancheng Bioengineering Institute). Three milliliters of diluted reagent were pipetted into $50 \mu \mathrm{l}$ of sample solution. The mixture was then incubated at room temperature for $10 \mathrm{~min}$. The absorbance was measured at $595 \mathrm{~nm}$. $\beta$-glucosidase activity assay was performed by monitoring the release of glucose or reducing sugar from cellobiose and salicin. Enzyme preparation, $500 \mu 1$, was incubated in the presence of $500 \mu \mathrm{l}(1 \% \mathrm{w} / \mathrm{v})$ substrate in $50 \mathrm{mM}$ citric-phosphate buffer $\mathrm{pH} 5$ at $50^{\circ} \mathrm{C}$ for $30 \mathrm{~min}$. Amount of glucose or reducing sugar released was measured with a glucose determination kit (Rongsheng Biotech Co) as described in the manufacturer's instructions. One international unit (IU) of enzyme activity was defined as the amount of enzyme that releases one micromole of glucose per minute under assay conditions. Specific activity was expressed as unit per milligram of protein.

\subsubsection{Optimum $\mathrm{pH}$ and temperature}

The $\mathrm{pH}$ optima for $\beta$-glucosidase activity was determined by performing assay at $50^{\circ} \mathrm{C}$, in sodium phosphate buffer $(50 \mathrm{mM})$ with $\mathrm{pH}$ values of $3.3,4.5,5,6.5,7.3$ and 8 . For optimum temperature assay, $\beta$-glucosidase activity was assayed at temperature $30,40,50,60,70$, and $80^{\circ} \mathrm{C}$ in sodium phosphate buffer $(50 \mathrm{mM}$, pH 5$)$. All reactions for activity test were carried out as previously described.

\section{Results and discussion}

\subsection{Construction of expression vector and screening of positive transformants}

The full length DNA of synthetic $\beta$-glucosidase gene was inserted into pPIC9K vector and transformed into $E$. coli DH5 $\alpha$ to give pPIC9K- $\beta$ G12 expression plasmid. The plasmid pPIC9K- $\beta$ G12 contained an insert with 2526 bp; confirmation of insertion was achieved by PCR (fig 1) and DNA sequencing. Figure 2 shows the nucleotide sequence of the insert DNA. It encodes a polypeptide of 841 amino acids with a predicted pI value of 4.52, having an estimated molecular weight of $91.5 \mathrm{kDa}$. A BLAST search against sequences deposited in the GenBank database revealed that the $\beta \mathrm{Gl} 2$ contains conserved domains which belong to glycosyl hydrolysis family 3 . Figure 3 presents amino acid alignment of $\beta \mathrm{Gl} 2$ with other isolated beta-glucosidases. The target gene was cloned in frame and downstream of the $\alpha$-factor signal sequence to allow secretion of the recombinant protein into the culture medium. In addition pPIC9K vector contains the AOX1 promoter that allows methanol-inducible high level expression in Pichia. Plasmid pPIC9K-BG12 was prepared, then linearized and transformed into the genome of P. pastoris strain GS115 and plated on MD plates. His ${ }^{+}$transformants were observed after three days. Transformants could only grow on plates containing G418 at $0.25 \mathrm{mg} / \mathrm{ml}$ when screened for multi integration of the $\beta G 12$ gene. Subsequently, integration of the gene into the P. pastoris genome was verified on seven G418 resistant clone by PCR, using 5'AOX1 and 3'AOX1 primers. Figure 4 shows a successful PCR amplicon with the size of $\sim 2500$ bp for five of the seven selected clones, meaning integration of $\beta \mathrm{Gl} 2$ gene downstream of AOX1 promoter in their genome. In addition, by yielding two products after PCR reaction, selected transformants appeared to be Mut ${ }^{+}$phenotype (methanol utilization fast).

\subsection{Expression of recombinant $\beta$-glucosidase in Pichia pastoris}

Time-course for $\beta$-glucosidase production in the culture medium was studied for 80 hours (fig 5). The presence of the recombinant protein was checked via SDS-PAGE analysis on sample prepared as described (material and methods). The enzyme was successfully excreted into the culture medium by $P$. pastoris from pPIC9K- $\beta$ Gl2 vector, using $1 \%$ final concentration of methanol as inducer. AOX1 gene in P. pastoris is tightly regulated and induced by methanol to high levels (Higgins and Cregg, 1998). A protein band corresponding to the recombinant $\beta$-glucosidase ( $\mathrm{r} \beta \mathrm{Gl} 2$ ) could be detected by coomassie Blue staining 24 hours after induction (fig 5). The production of glucosidase was increasing and reached maximum after 60 hours of induction. Accordingly, the subsequent experiments of beta-glucosidase were carried out with an induction time of 60 hours.

\subsection{Enzyme production and purification}

The recombinant beta-glucosidase produced by Pichia pastoris was purified from the culture supernatant. Summary of purification steps was recorded in table 1. Ammonium sulfate fractionation at range $30-80 \%$ saturation produced around $61 \%$ of protein from the initial protein amount in the supernatant. This fraction retained much of the enzyme activity $(\sim 87 \%)$. The precipitated enzyme was then bound to DEAE-cellulose at $10 \mathrm{mM}$ phosphate buffer, $\mathrm{pH} 7.0$. Elution of the column using a linear sodium chloride gradient could further remove about $80 \%$ contaminating protein from the previous step (or $\sim 87 \%$ protein from the culture filtrate). In this step, $\beta$-glucosidase was purified 3.1 fold with a yield of $42.6 \%$. The final purification was achieved by gel filtration through Sephadex G-200. This resulted in an increase of the purity by about 2 times from 
DEAE-cellulose. By these steps, the specific $\beta$-glucosidase activity reached $51.2 \mathrm{U}_{\mathrm{mg}}{ }^{-1}$. A similar protocol using Sephacryl 300 yielded approximatives results during purification of a plant $\beta$-glucosidase (Rakrudee, 2004). The denatured enzyme (boiled for $10 \mathrm{~min}$ in the presence of $\beta$-mercaptoethanol) showed a single homogenous band, having an apparent molecular mass of approximately $90 \mathrm{kDa}$ (fig 6), which is consistent with the predicted value from deduced protein encoded by the cloned gene.

\subsection{Effect of pH and temperature on enzyme activity}

The recombinant $\beta$-glucosidase secreted by Pichia pastoris was assayed for cellobiose and salicin hydrolysis. The enzyme was most active towards cellobiose $[17.7 \mathrm{U} / \mathrm{ml}$ against $3.9 \mathrm{U} / \mathrm{ml}$ for salicin at optimum conditions (fig 7)]. The optimum $\mathrm{pH}$ was 5.0 for both substrates as shown in figure 7 (A). The activity decreased at $\mathrm{pH}$ above 5. Salicinase and cellobiase activities were highest at temperatures of 40 and $50^{\circ} \mathrm{C}$ respectively. Similar properties were observed for some $\beta$-glucosidases (Dhake and Patil, 2005; Pornphimon, 2005, Zhou and Yin, 2009).

Overexpression of beta-glucosidase in Pichia pastoris offers an advantage for its large scale production via fermentation for industrial bioconversion processes. In addition, construction of yeast expressing cellulases appear to be very useful for simultaneous saccharification and fermentation

\section{References}

Aristidou, A. and Penttila, M. (2000). Metabolic engineering application to renewable resource utilization. Current Opinion in Biotechnology, 11, 187-188

Baht, M. K., and Bhat, S. (1997). Cellulose degrading enzymes and their potential industrial application. Biotechnology Advances, 15(3), 583-620

Cereghino, J. L. and Cregg, J.M. (2000). Heterologous Protein Expression in the Methylotrophic Yeast Pichia pastoris. FEMS Microbiology Reviews. 24, p. 45

Dhake, A. B. and Patil, M. B. (2005). Production of $\beta$-glucosidase by Penicillium purpurogenum. Brazilian Journal of Microbiology, 36: 170-176.

Dien, B. S., Cotta, M. A. and Jeffries, T. W. (2003). Bacteria engineered for fuel ethanol production: Current Status. Applied Microbiology Biotechnology, 63 (3), 258-266.

Fujita, Y., Takahashi S., Ueda M., Tanaka A., Okada H., Morikawa Y., Kawaguchi T., Arai M., Fukuda H., and Kondo A. (2002). Direct and efficient production of ethanol from cellulosic material with a yeast strain displaying cellulolytic enzymes. Applied and Environmental Microbiology, 68 (10) 5136-5141.

Harju, S., Fedosyuk, H. and Peterson, K. R. (2004). Rapid isolation of yeast genomic DNA: Bust n' Grab BMC Biotechnology, 4, 8 [Online] Available: http://www.biomedcentral.com/1472-6750/4/8.

Hasslacher, M., Schall, M., Hayn, M., Bona, R., Rumbold, K., Luckl, J., Griengl H., Kohlwein and Schwab. (1997). High level intracellular expression of hydroxynitrite lyase from the tropical rubber tree Hevea brasikiensis in microbial hosts. Protein Expression Purification,11 (1) 61-71.

Higgins, D. R. and Cregg, J. (1998). Introduction to Pichia pastoris. In Pichia Protocols. Methods in Molecular Biology, 103 (pp 2-13). Human Press, Totowa, New Jersey.

Hollenberg, C. P. and Gellissent G. (1997). Production of recombinant proteins by methylotropic yeast. Current Opinion in Biotechnology, 8 (5), 554-560.

Hong J., Tamaki H., Kumagai, H. (2006). Cloning and functional expression of thermostable $\beta$-glucosidase gene from Thermoascus aurantiacus. Applied Biochemistry and Biotechnology, 73 1331-1339

Invitrogen. (2000). Pichia expression kit: a manual of methods for expression of recombinant proteins in Pichia pastoris. L ed. Invitrogen Corporation, Carlsbad, Calif.

Jeon E., Hyeon J-E., Suh D. J., Suh Y-W., Kim S. W., Song K. H. and Han S. O. (2009). Production of cellulosic ethanol in Saccharomyces cerevisiae heterologous expressing Clostridium thermocellum endoglucanase and Saccharomycopsis fibuligera. Molecules and cells 28. 369-373

Laemmali, U. K. (1970). Cleavage of structural protein during the assembly of the head of bacteriolophage T4. Nature, 227, 680-685

Li, P., Anumanthan, A., Gao, X. G., Ilangovan, K., Suzara, V. V., Duzgunes N. and Renugopalakrishnan. (2007). Expression of recombinant proteins in Pichia pastoris. Applied Biochemistry and Biotechnology, 142 (2) $105-124$ 
Lynd, L. R., Weimer, P. J., Van Zyl, W. H., Pretorius, I. S. (2002). Microbial cellulose utilization: Fundamentals and biotechnology. Microbiology and Molecular Biology Reviews, 66 (3) 506-577

Pornphimon, M. (2005). Recombinant expression of $\beta$-glucosidase from Thai Rosewood (Dalbergia cochinchinensis Pierre) in yeast. $\mathrm{PhD}$ thesis in Biochemistry Suranaree University of Technology. [Online] Available: http://sutir.sut.ac.th:8080/ sutir/bitstream/123456789/1703/1/Pornphimon.pdf

Rakrudee, S. (2004). Plant $\beta$-glucosidase: Study of transglucosylation of long chain alcohols and crystallization of Thai Rosewood $\beta$-glucosidase. Doctor Degree thesis. Faculty of graduates studies, Mahidol University.

Ryu D.D.Y. and Mandels M. (1980). Cellulases: Biosynthesis and applications Enzyme and Microbiological Technology, 2 (2) 91-102

Sambrook, J. and Russell, D. W. (2001). Plasmids and their usefulness in molecular cloning. In Molecular Cloning: A laboratory manual $3^{\text {rd }}$ Ed., vol 2. Cold Spring Harbor Laboratory Press, Harbor New York.

Sreekrishna K., Brankamp, R. G. Kropp, K. E. Blankenship, Tsay, J. T. Smith P. L; Wierschke J. D. Subramanian A. and Birkenberger. (1997). Stragtegies for optimal synthesis and secretion of heterologous protein in the methylotrophic yeast Pichia pastoris. Gene, 190 (1), 55-62

Van Rensburg, P., Van Zyl W. H., and Pretorius I. S. (1998). Engineering yeast for efficient cellulose degradation. Yeast, 14. 67-76

Wood, T.M., and McCrae, S. I. (1982). Purification and some properties of the extracellular $\beta$-glucosidase of the cellulolytic fungus Trichoderma koningii. Journal of General Microbiology, 128, 2973-2982

Zhou jin and Yin peng. (2009). Expression and one-step purification of glucosidase in Pichia pastoris. The Chinese journal of process engineering, 9 (5) 981-986

Table 1. Summary of purification of recombinant $\beta$-glucosidase from Pichia pastoris

\begin{tabular}{|c|c|c|c|c|c|}
\hline Purification steps & $\begin{array}{c}\text { Total } \\
\text { activity } \\
(\mathbf{U})\end{array}$ & $\begin{array}{c}\text { Total protein } \\
\text { (mg) }\end{array}$ & $\begin{array}{c}\text { Specific } \\
\text { activity } \\
\text { (U/mg protein) }\end{array}$ & $\begin{array}{c}\text { Fold } \\
\text { purification }\end{array}$ & $\begin{array}{c}\text { Yield } \\
\text { (\% recovery) }\end{array}$ \\
\hline Culture filtrate & 313.56 & 45.36 & 6.9 & - & - \\
\hline Ammonium sulfate & 275.6 & 27.8 & 9.9 & 1.4 & 87.9 \\
\hline DEAE-cellulose & 117.34 & 5.45 & 21.53 & 3.1 & 37.42 \\
\hline Sephadex G-200 & 42.56 & 0.83 & 51.2 & 7.4 & 13.6 \\
\hline
\end{tabular}

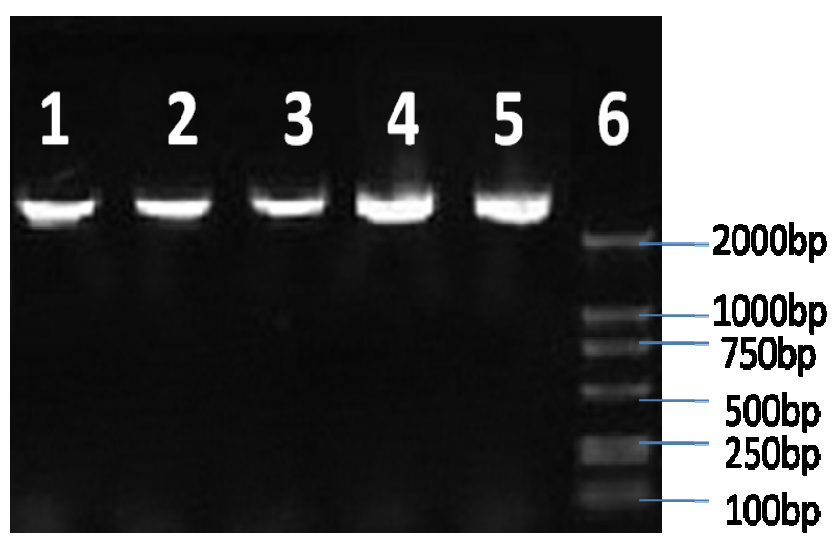

Figure 1. Screening of DH5 $\alpha$ transformants harboring the expression vector pPIC9K- $\beta$ Gl2. Colony PCR was performed using selected colonies from LB plate + ampicillin. An aliquot of PCR product were analyzed by electrophoresis on $0.8 \%$ agarose gel, Lane 1 to 4; Lane 5: plasmid pUC19-ßGL2. Lane 6: DNA marker 


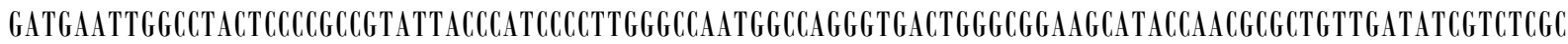

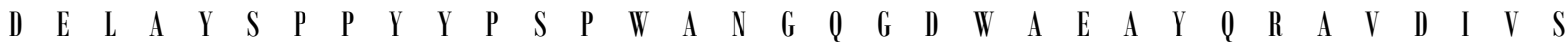
AGATGACATTGGCTGAGAAGGTCAATTTGACTACGGGAACTGGATGGGAATTGGAATTATGTGTTGGTCAGACTGGAGGTGTTCCGCGGTTGGGAATTCC

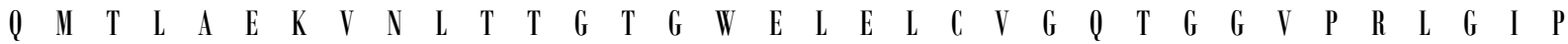
GGGATGTGTGCACAGGATAGCCCTCTGGGTGTTCGTGACTCCGACTACAACTCTGCGTTCCCTGCCGGTGTCACGTGGCCGCAACCTGGGACAAGAAT $\begin{array}{llllllllllllllllllllllllllllllllll}\text { G } & \text { II } & \text { C } & \text { A } & \text { Q } & \text { D) } & \text { S } & \text { P } & \text { L } & \text { G } & \text { V } & \text { R } & \text { D } & \text { S } & \text { D } & \text { Y } & \text { N } & \text { S } & \text { A } & \text { F } & \text { P } & \text { A } & \text { G } & \text { V } & \text { N } & \text { V } & \text { A } & \text { A } & \text { T } & \text { W } & \text { D } & \text { K } & \text { N }\end{array}$

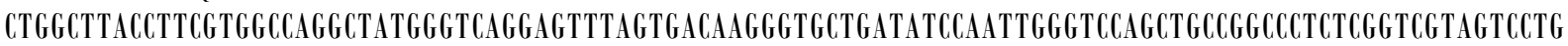
L

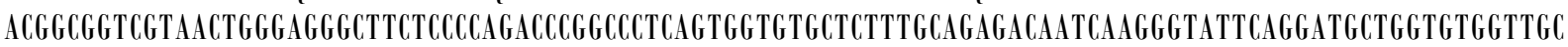

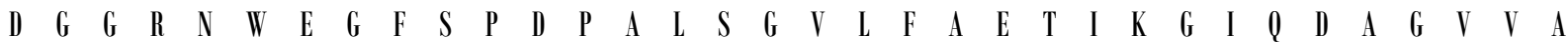

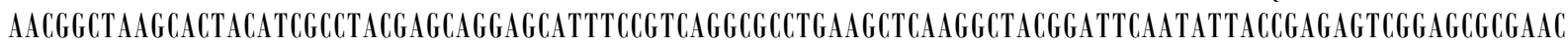
$\begin{array}{llllllllllllllllllllllllllllllllll}\mathrm{T} & \mathrm{A} & \mathrm{K} & \mathrm{H} & \mathrm{Y} & \mathrm{I} & \mathrm{A} & \mathrm{Y} & \mathrm{E} & \mathbf{Q} & \mathrm{E} & \mathrm{H} & \mathrm{F} & \mathrm{R} & \mathbf{Q} & \mathrm{A} & \mathrm{P} & \mathrm{E} & \mathrm{A} & \mathbf{Q} & \mathrm{G} & \mathrm{Y} & \mathrm{G} & \mathrm{F} & \mathrm{N} & \mathrm{I} & \mathrm{T} & \mathrm{E} & \mathrm{S} & \mathrm{R} & \mathrm{S} & \mathrm{A} & \mathrm{N}\end{array}$

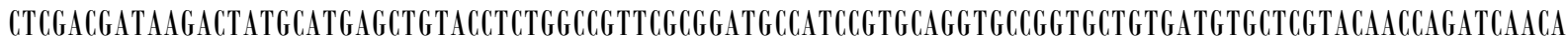

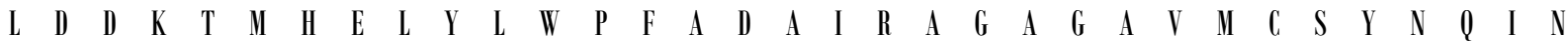
ACAGCTATGGCTGCCAAAACAGCTACACTCTGAACAAGCTGCTCAAGGCTGAGCTGGGTTTCCAGGgCTTTGTCATGAGTGATTGGGCGGCTCACCATGC $\begin{array}{llllllllllllllllllllllllllllllllll}N & S & \text { Y } & G & C & \text { Q } & \text { N } & \text { S } & \text { Y } & \text { T } & \text { L } & \text { N } & \text { K } & \text { L } & \text { L } & \text { K } & \text { A } & \text { E } & \text { L } & \text { G } & \text { F } & \text { Q } & \text { G } & \text { F } & \text { V } & \text { II } & \text { S } & \text { D } & \text { W } & \text { A } & \text { A } & \text { H } & \text { H } & \text { A }\end{array}$

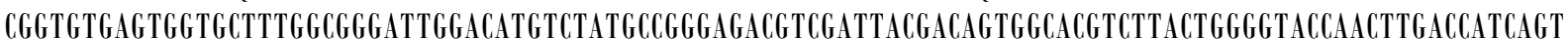

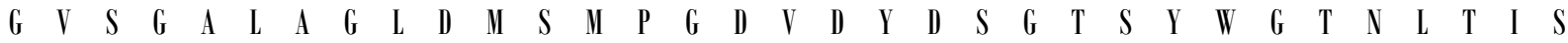

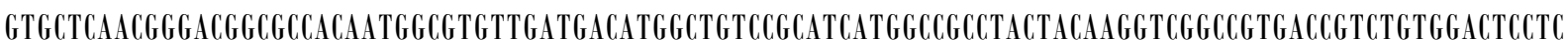
$\begin{array}{lllllllllllllllllllllllllllllllll}\text { V } & \text { L } & \text { N } & \text { G } & \text { T } & \text { A } & \text { P } & \text { Q } & \text { W } & \text { R } & \text { V } & \text { D } & \text { D } & \text { II } & \text { A } & \text { V } & \text { R } & \text { I } & \text { II } & \text { A } & \text { A } & \text { Y } & \text { Y } & \text { K } & \text { V } & \text { G } & \text { R } & \text { D } & \text { R } & \text { L } & \mathbb{W} & \text { T } & \text { P }\end{array}$

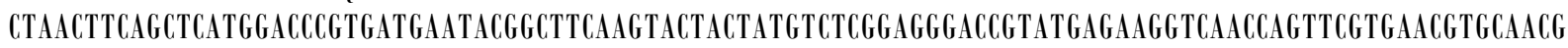

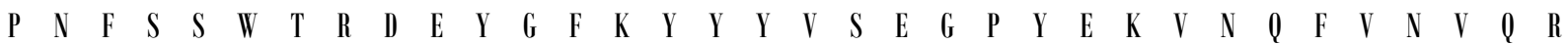
CAACCATAGCGAGTTGATCCGCCGTATTGGAGCAGACAGCACGGTGCTCCTCAAGAACGATGGCGCTCTTCCATTGACTGGAAAGGAGCGCTTGGTCGCC $\begin{array}{lllllllllllllllllllllllllllllllll}\mathbf{N} & \text { H } & \text { S } & \text { E } & \text { L } & \text { I } & \text { R } & \text { R } & \text { I } & \text { G } & \text { A } & \text { J } & \text { S } & \text { T } & \text { V } & \text { L } & \text { L } & \text { K } & \text { N } & \text { J } & \text { G } & \text { A } & \text { L } & \text { P } & \text { L } & \text { T } & \text { G } & \text { K } & \text { E } & \text { R } & \text { L } & \text { V } & \text { A }\end{array}$ CTTATCGGAGAaGATGCGGGTTCCAATCCTTATGGTGCCAACGGCTGCAGTGACCGTGGGTGCGACAATGGACATTGGCGATGGGCTGGGGAaGTGGCA

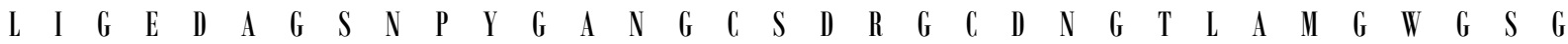
CTGCCAACTTTCGGTACTTGGTGaCCCCTGaGCAGGCCATCTCGAACGaGgTGCTCAaGAaCAAGAATGGCGTATTCACTGCGACCGATAACTGGGCTAT $\begin{array}{llllllllllllllllllllllllllllllllll}T & \text { A } & \text { N } & \text { F } & \text { P } & \text { Y } & \text { L } & \text { V } & \text { T } & \text { P } & \text { E } & \text { Q } & \text { A } & \text { I } & \text { S } & \text { N } & \text { E } & \text { V } & \text { L } & \text { K } & \text { N } & \text { K } & \text { N } & \text { G } & \text { V } & \text { F } & \text { T } & \text { A } & \text { T } & \text { D } & \text { N } & \text { W } & \text { A } & \text { I }\end{array}$

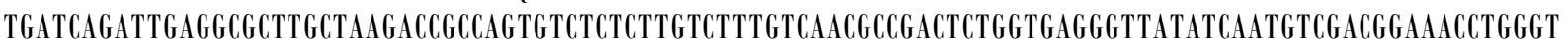

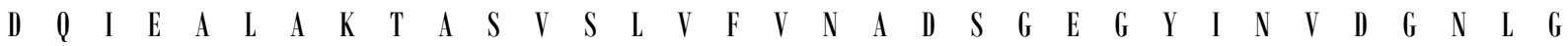

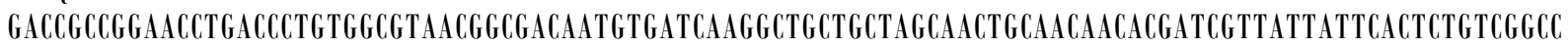

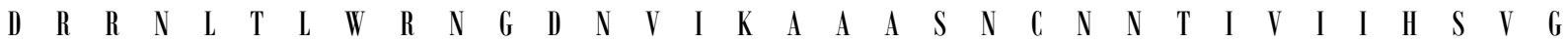

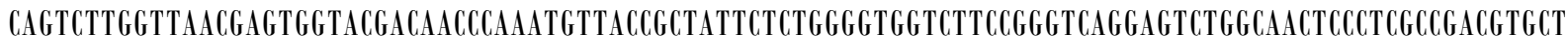
$\begin{array}{lllllllllllllllllllllllllllllllllll}P & \text { V } & \text { L } & \text { V } & \text { N } & \text { E } & \mathbb{W} & \text { Y } & \text { D } & \text { N } & \text { P } & \text { N } & \text { V } & \text { T } & \text { A } & \text { I } & \text { L } & \text { W } & \text { G } & \text { G } & \text { L } & \text { P } & \text { G } & \text { Q } & \text { E } & \text { S } & \text { G } & \text { N } & \text { S } & \text { L } & \text { A } & \text { D } & \text { V } & \text { L }\end{array}$

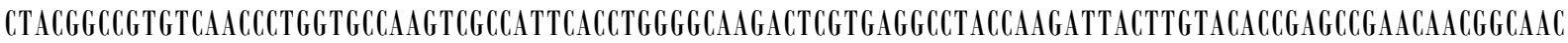
$\begin{array}{lllllllllllllllllllllllllllllllll}\text { I } & G & R & \text { V } & \text { N } & \text { P } & \text { G } & \text { A } & \text { K } & \text { S } & \text { P } & \text { F } & \text { T } & \text { W } & \text { G } & \text { K } & \text { T } & \text { R } & \text { E } & \text { A } & \text { Y } & \text { Q } & \text { J } & \text { Y } & \text { L } & \text { Y } & \text { T } & \text { E } & \text { P } & \text { N } & \text { N } & \text { G } & \text { N }\end{array}$

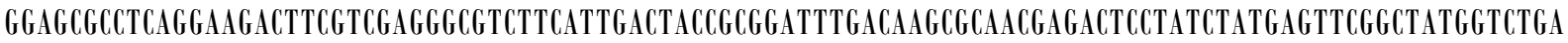
G

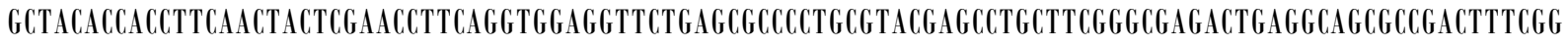
$\begin{array}{lllllllllllllllllllllllllllllllllll}S & Y & T & T & F & N & Y & S & N & L & Q & V & E & V & L & S & A & P & A & Y & E & P & A & S & G & E & T & E & A & A & P & T & F & G\end{array}$

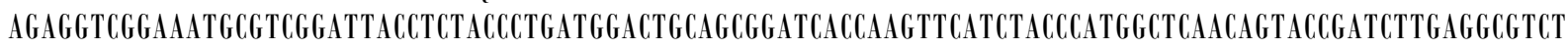

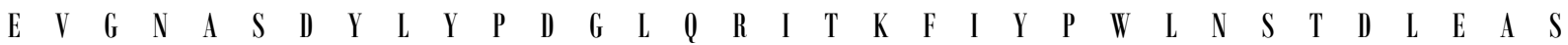

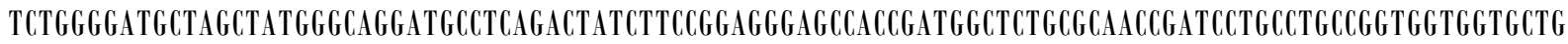
$\begin{array}{llllllllllllllllllllllllllllllllll}S & G & \text { D } & \text { A } & S & \text { Y } & G & \text { Q } & \text { D } & \text { A } & \text { S } & \text { DJ } & \text { Y } & \text { L } & \text { P } & \text { E } & G & \text { A } & \text { T } & \text { D } & G & \text { G } & \text { A } & \text { Q } & \text { P } & \text { I } & \text { L } & \text { P } & \text { A } & \text { G } & G & G & \text { A }\end{array}$

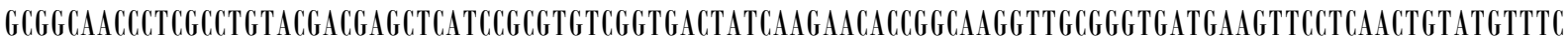

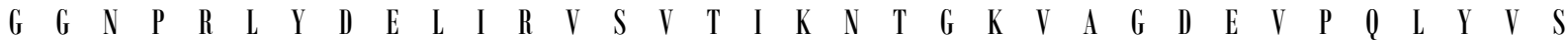

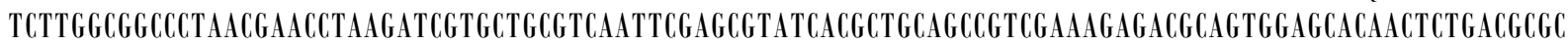

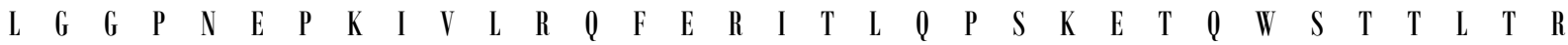

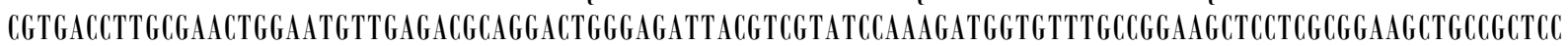
$\begin{array}{llllllllllllllllllllllllllllllllll}R & \text { I) } & \text { L } & \text { A } & \text { N } & \mathbb{W} & \text { N } & \text { V } & \text { E } & \text { T } & \text { Q } & \text { I) } & \mathbb{W} & \text { E } & \text { I } & \text { T } & \text { S } & \text { Y } & \text { P } & \text { K } & \text { II } & \text { V } & \text { F } & \text { A } & \text { G } & \text { S } & \text { S } & \text { S } & \text { R } & \text { K } & \text { L } & \text { P } & \text { L }\end{array}$ gGGGGTCTCTGCCTACTGTTCACTAa

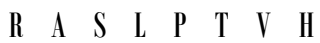

Figure 2. Nucleotide and deduced amino acid sequences of $\beta$-glucosidase 
BGL2 141 SPDGGRNWEGSPDPALSGVLFAETIKGIQDAGVVATAKHYIAYEQEHFR---gYgfniTeSRSANLDDKT 214

AGCBG1 105 SGLNGRNEECYSEDPALTAACAVAYINGVQSQGVAATIKHFVANESEIER---------Q-TMSSDVDERT 165

PABGL 164 KAAGGRGWEGHGPDPYLEGVIAYLQTIGIQSQGVVSTAKHLIGNEQEHFR--------tSSSLSSEIDDRA 243

ACABGL 152 SPDGGRNWEGSSDPVNSGLLVAETIKGIQSAGVIACVKHFIGNEQERFR---gYg fdiSeSSSSNIDDVT 225

AACBGL 151 SPDGGRNWEGFSPDPATGVLFAETIKGIQDAGVVATAKHY ILNEQEHFR---gyg fniSATISSNVDDKT 224

SFBGL1 165 KARGGRNFEAFGSDPYLQGTAAAATIKGLQENNVMACVKHFIGNEQEKYR---atnqttKeAISANIPDRA 239

CHBGL1 156 KPRGGRNWEGFGSPVLQAFGGSLSVEGIQSTGVIATIKHLIANEQEMYR-------i iVKPGYSSNVDDRT 222

CIBGL1 167 KPRGGRNWEGFGSDPSLQAIAAVETIKGVQSKGVIATIKHLVGNEQEMYR-------ivQYAYSANIDDRT 233

KCBGLN 161 VATGGRNWEGTNDPYLAGALVYETTKGIQ-ENVIACTKHFIGNEQETNR------gtyNGSVSANIDDKT 227

Figure 3. Alignment of $\beta$ GL2 amino acid with other glycosyl hydrolases family. Conserved residues are highlighted. AGCBG1 represents Agrobacterium tumefaciens CBG1 (Accession n P27034), PABGL1 represents Pichia anomala BGL (Accession $n^{\circ}$ P06835), ACABGL represents Ajellomyces capsulatus (Accession $\left.\mathrm{n}^{\circ} \mathrm{Q} 00025\right)$, AACBGL represents Aspergillus aculeatus BGL1 (Accession $\mathrm{n}^{\circ}$ P48825), SFBGL1 represents Saccharomycopsis fibuligera BGL1 (accession n P22506), CHBGL1 represents Cochliobolus heterostrophus BGL1 (Accession ${ }^{\circ}$ O13385), CIBGL1 represents Coccidioides immitis BGL1 (Accession ${ }^{\circ}$ O14424), KCBGLN represents Kuraishia capsulate BGLN (Accession n ${ }^{\circ}$ Q12653), BGL2 represents Beta-glucosidase (this study).

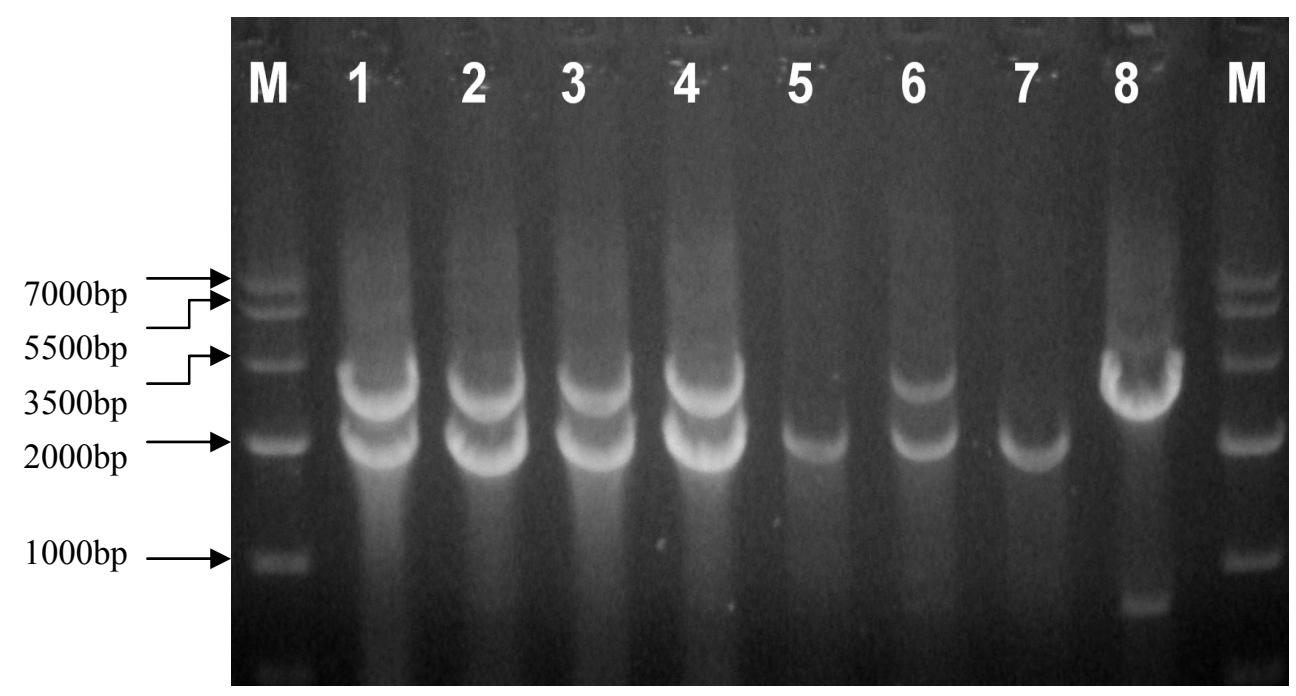

Figure 4. PCR analysis of the $\beta$-glucosidase gene ( $\beta$ GL2) integration. Genomic DNA of Pichia pastoris clones transformed by pPIC9K- $\beta$ GL2 was analyzed by PCR using AOX1-specific primers. Integrated sequence yields a PCR product of 2526bp while the wild-type AOX1 gene yields a product of 2200bp. Clones 1 to 4 and 6 had incorporated the $\beta$ GL2 sequence; Clones 5 and 7 were false positives; Lane 8: Control pPIC9K- $\beta$ GL2 plasmid. M: molecular marker. 


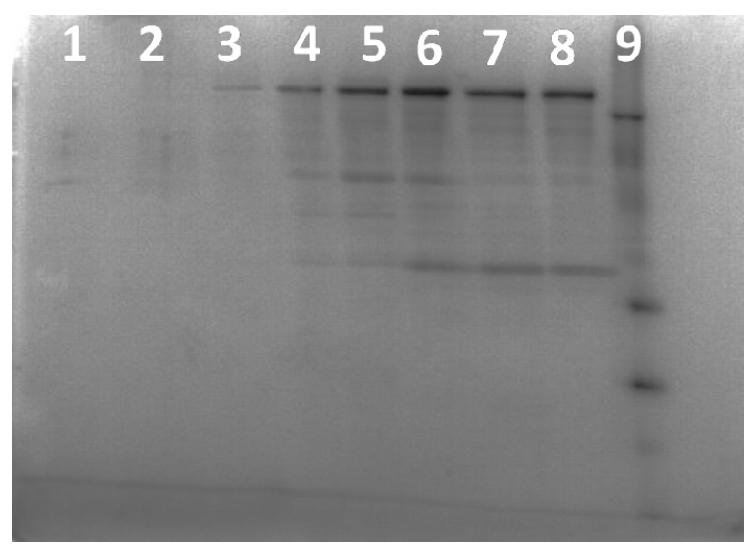

Figure 5. Time course production of $\beta$-glucosidase into the induction medium. Samples were taken from the Pichia pastoris culture medium at time intervals 0h (lane1), 12h (lane 2), 24h (lane 3), 36h (lane 4), 48 (lane 5), 60h (lane 6), 72h (lane7) and 80h (lane 8). Level of expression was measured on supernatants on $10 \%$ SDS-PAGE gel. High level was after 60 hours induction (Lane 6). Marker (Lane 9).

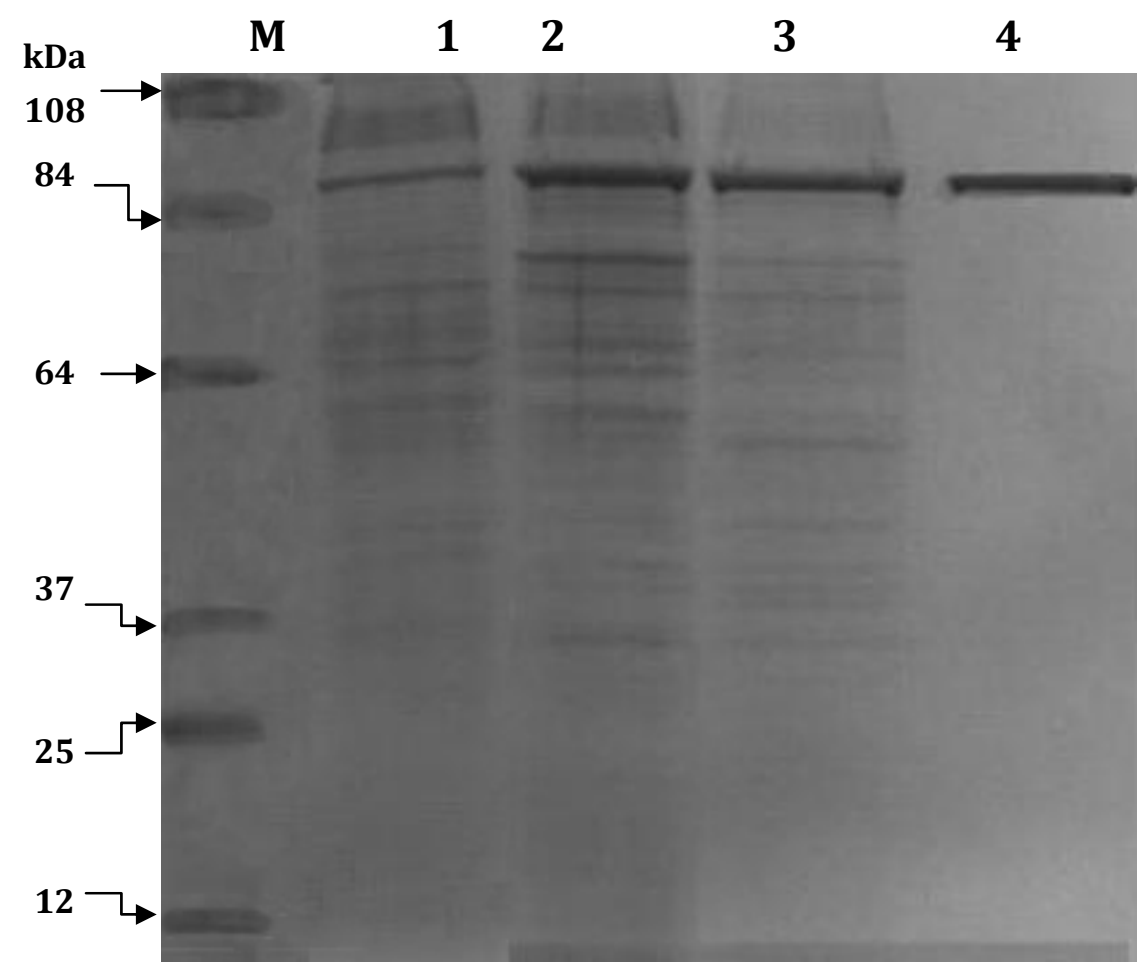

Figure 6. SDS-PAGE profile $\beta$-glucosidase purification's steps. Lane 1 Molecular marker, Lane 2: culture supernatant, Lane 3: 30-80\% ammonium sulfate fraction, Lane 4: DEAE-cellulose, Lane 5: purified $\beta$-glucosidase 


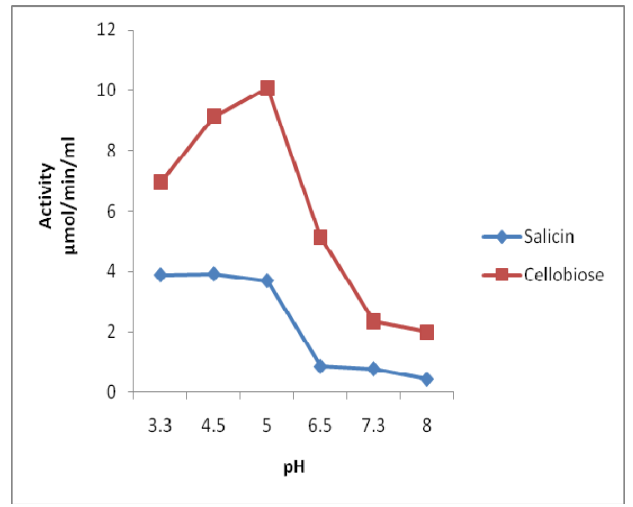

Fig 7 (A)

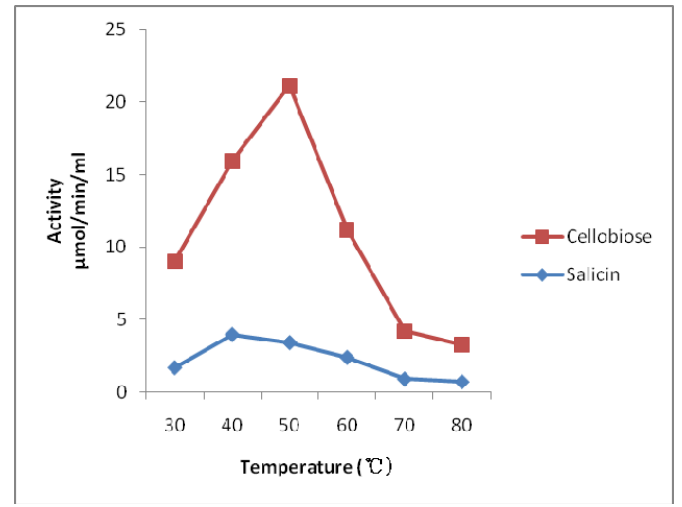

Fig 7 (B)

Figure 7. Determination of the optimum $\mathrm{pH}$ and temperature of recombinant $\beta$-glucosidase activity. The enzyme activity was tested in presence of cellobiose and salicin at different $\mathrm{pH}$, ranging from 3.3 to 8 (A) and at different temperature from 30 to $80^{\circ} \mathrm{C}(\mathrm{B})$ 